\title{
ESL Teachers' Readiness During Covid 19: Guglielmino Readiness Scale
}

\author{
Said Fathi ${ }^{1}$ 8(D) and Aziz Moummou ${ }^{2}$ (D) $\square$ \\ ${ }^{1}$ Professor of linguistics at faculty of Letters and Humanities, Mohammedia, Hassan II university, Morocco \\ ${ }^{2}$ PhD. Candidate, Laboratory of Language, Literature and Translation, Faculty of Letters and Humanities, Mohammedia Hassan \\ University, Morocco
}

$\triangle$ Corresponding Author: Aziz Moummou, E-mail: azizmoummou@gmail.com

\section{ARTICLE INFORMATION ABSTRACT}

Received: March 08, 2021

Accepted: April 10, 2021

Volume: 3

Issue: 4

DOI: $10.32996 /$ jhsss.2021.3.4.1

\section{KEYWORDS}

Language policy, self-

management, local agents, COVID

19, language management,

Guglielmino readiness scale
The new line of research in language policy and planning acknowledges the importance of decentralized language policy decisions. There is widespread dissatisfaction with central governments' top-down approach, and it is time to redirect the wheels. Covid 19 imposed a hybrid education model in Morocco: teacherdirected versus self-directed learning. The purpose of this paper is to investigate ESL teachers' readiness in sustaining a self-directed learning language policy using Guglielmino readiness scale. The results will sustain research in critical language policy and seek ways to involve teachers in policymaking.

\section{Introduction}

Early language policy and planning adopted an ahistorical philosophy where language planners chained ideas into one line of thought: if economic planning is possible, language planning should not be different. Experience showed a sobering picture. Most traditional language planning efforts resulted in conflict and resistance. According to Tollefson, classical language policy and planning "acknowledges that policies often create and sustain various forms of social inequality and that policy-makers usually promote the interests of dominant social groups" (Tollefson, 2006, p.42). Therefore, speech communities resisted the imposed language policies and developed decentralized interpretations. Language management theory promises a collaborative framework to mediate between policymakers and local agents (in this paper ESL teachers). Using Guglielmino's self-directed learning readiness scale, we will consider:

1- How did ESL teachers in Morocco translate the ministry's circular (39/20) about self-directed learning policy during COVID 19?

2- How can the language management model improve synchrony between language policy and local practices?

\section{Research model}

To examine local agents' role in producing effective language policies, we will use the language management model. Spolsky's use of the term 'management' instead of 'planning' marks a turn in LPP. Language planning is associated with post-modernist and newly independent states, especially in Africa, to create a post-colonial linguistic identity. It was administered by central governments and aimed at standardized, monolingual societies. For example, Morocco declared 'Arabization' right after independence to avoid the curse of bilingualism and build a unified national identity. The management model adopts a critical approach to language planning. It advocates the centrality of microscopic practices over macro-level language policies. Spolsky identifies four main variables in the language management model: language beliefs and ideology, language practices, management, and self-management.

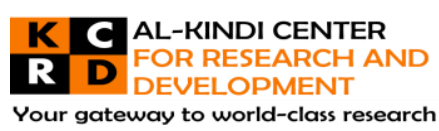

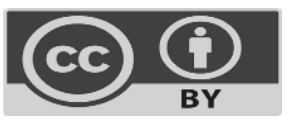

Published by Al-Kindi Center for Research and Development. Copyright (c) the author(s). This open access article is distributed under a Creative Commons Attribution (CC-BY) 4.0 license 


\section{Methodology}

In an attempt to assess teachers' readiness to participate in the creation of a self-directed learning language policy, we will use Guglielmino's scale. It is a tool for measuring attitudes, character traits and abilities. The scale's reliability is estimated at .94 (Guglielmino, 1989). 64 ESL teachers in secondary schools at the directorate of Chichaoua, Morocco, were asked to respond to an online questionnaire. 46 teachers responded, representing a 76\% response rate. Triangulation is used in order to check data's validity before reaching conclusions. The quantitative results retrieved from the questionnaire is supported by a qualitative content analysis of a group interview. The participants in this study were asked to provide the following information about themselves in an anonymous, self-report questionnaire: sex, age, level of education, level of independence at the workplace, feeling about ministry's support. Data was transcribed and coded using Nvivo according to the four language management theory variables: ideology, practices, self-management, and management.

\section{Results}

\section{1 Language beliefs and ideology}

Beliefs and ideology related to a particular language or variety rely on their importance in a speech community. Some languages promise better access to economic and social growth. Likewise, In Morocco, policymakers implicitly acknowledge English's importance, but French remains a de facto language. Respectively, teachers of English believe in their role as agents of change. They understand and benefit from the extrinsic motivation that surrounds English language acquisition. The questionnaire surveyed ESL teachers' belief about their readiness to stimulate change in language policy.

Figure 1: Teachers' readiness to participate in language policy during COVID 19 in Morocco.

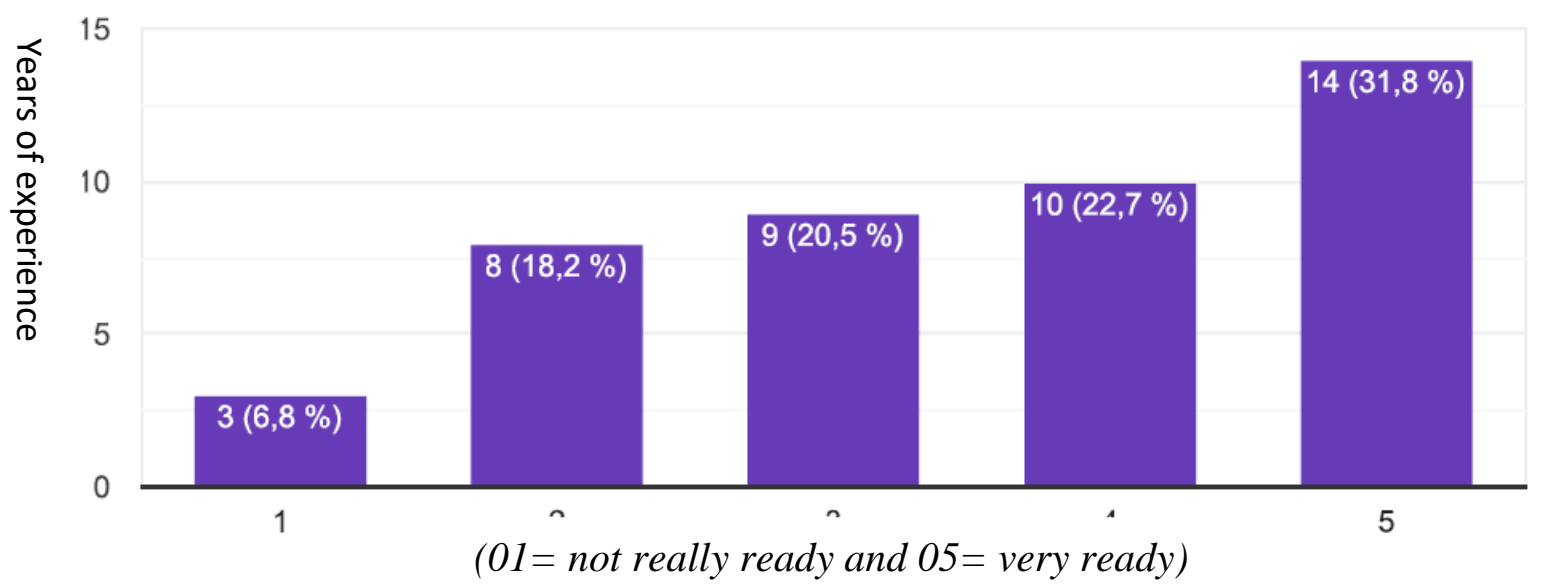

In figure 1 above, teachers were asked to rate their confidence in influencing language policy during COVID 19 on a five-point Likert scale of 1 to 5 (Not ready Vs very ready). Over $50 \%$ of respondents believe they can effectively contribute to language policy design during COVID 19. With a mean of 8.8. An analysis of individual answers showed that the majority of the respondents were junior teachers. One might contemplate those novice teachers with less than five years of experience are more resistant to central policies. Consonant to teachers' beliefs in their role as local policymakers, it is necessary to question teachers' self-directed learning practices before turning a skeptical eye on their ability to create a langue policy.

\subsection{Language Practices}

Spolsky (2009) posits that "Language practices are the observable behaviors and choices - what people actually do" (p.04). In this regard, we will examine teachers' self-directed learning skills and practices. The aim is not a mere analysis of causality but a sociolinguistic study of teachers'-students dynamics. First, self-directed learning covers a broad spectrum of meanings, for example, autonomous, independent and free learning. In his report published by the Council of Europe in 1979, Holec defined learner autonomy as "the ability to take charge of one's own learning $(1981, \mathrm{p}$. 3). This definition congregates the concept of independence, autonomy and freedom. In fact, learners' autonomy lies in their ability to make choices independently (learn online, focus on reading, practice listening, etc.). Knowles M. explained these principled choices as follows:

In its broadest meaning, "self-directed learning" describes a process in which individuals take the initiative, with or without the help of others, in diagnosing their learning needs, formulating learning goals, identifying human and material resources for learning, choosing and implementing appropriate learning strategies, and evaluating learning outcomes. (1975, p. 18) 
Figure 2: Teachers' self-directed practices

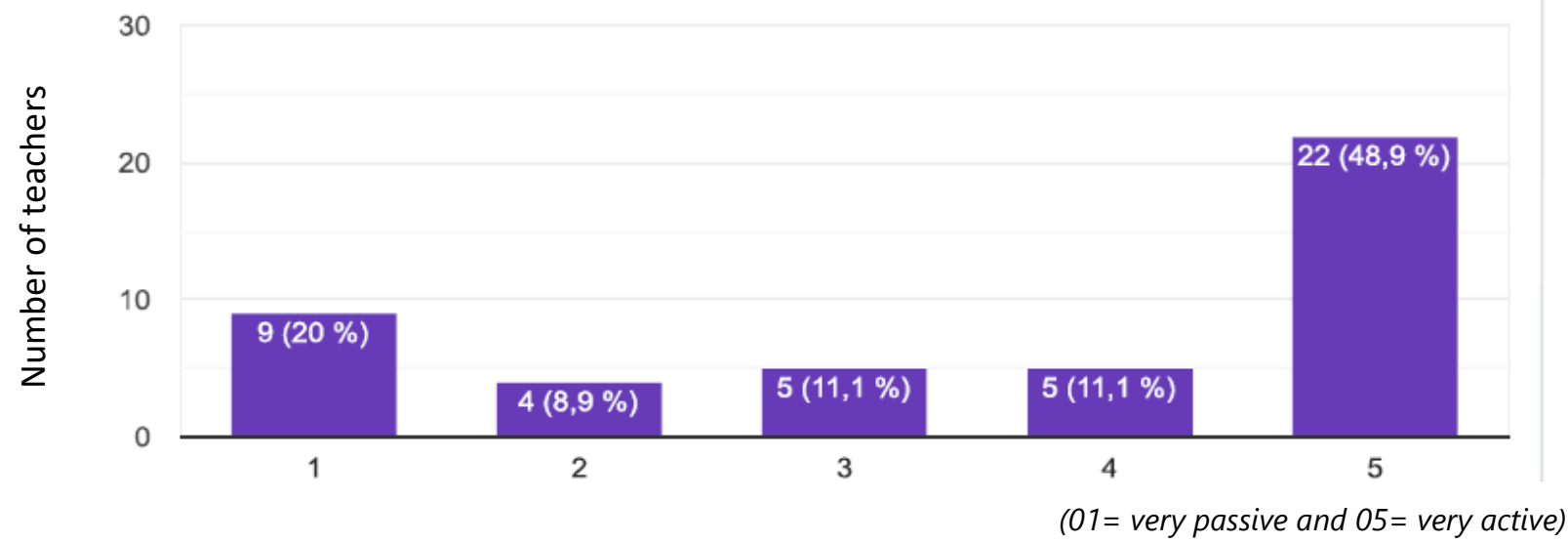

From the above argument, we understand that self-directed learning never occurs in a vacuum. It usually requires external factors, whether human, such as mentors, teachers, an advanced peer or logistical: computer-based learning, curriculum, MOOCs, etc. As mentioned before, students' self-directed learning will depend mainly on teachers' own autonomy.

Almost $60 \%$ of the respondents confirmed the use of online platforms for professional development. The answer with the highest mode (05) was about teachers self-training in exploring online teaching platforms during the pandemic, e.g., zoom, teams, google classroom, etc.

\subsection{Language management}

Agency is a key construct in language management. Policymakers, teachers, writers, etc., are authorities that decide about language choice. Management refers to language choices in multilingual societies where the decision is an outcome of collaboration between central policy and local practices. In a recent article, Spolsky distinguishes between two categories of management agents: managers with power and advocates without power (Spolsky, 2018, p.01). This study aims to examine ESL teachers' role as managers with power in advocating self-directed learning. Our concern is to define teachers' role concerning a national language policy of English language learning. Teachers need to act as mediators between educational authorities and students. But the figure below shows a sobering picture:

Figure 3: Teachers reflection on the ministry of education's support.

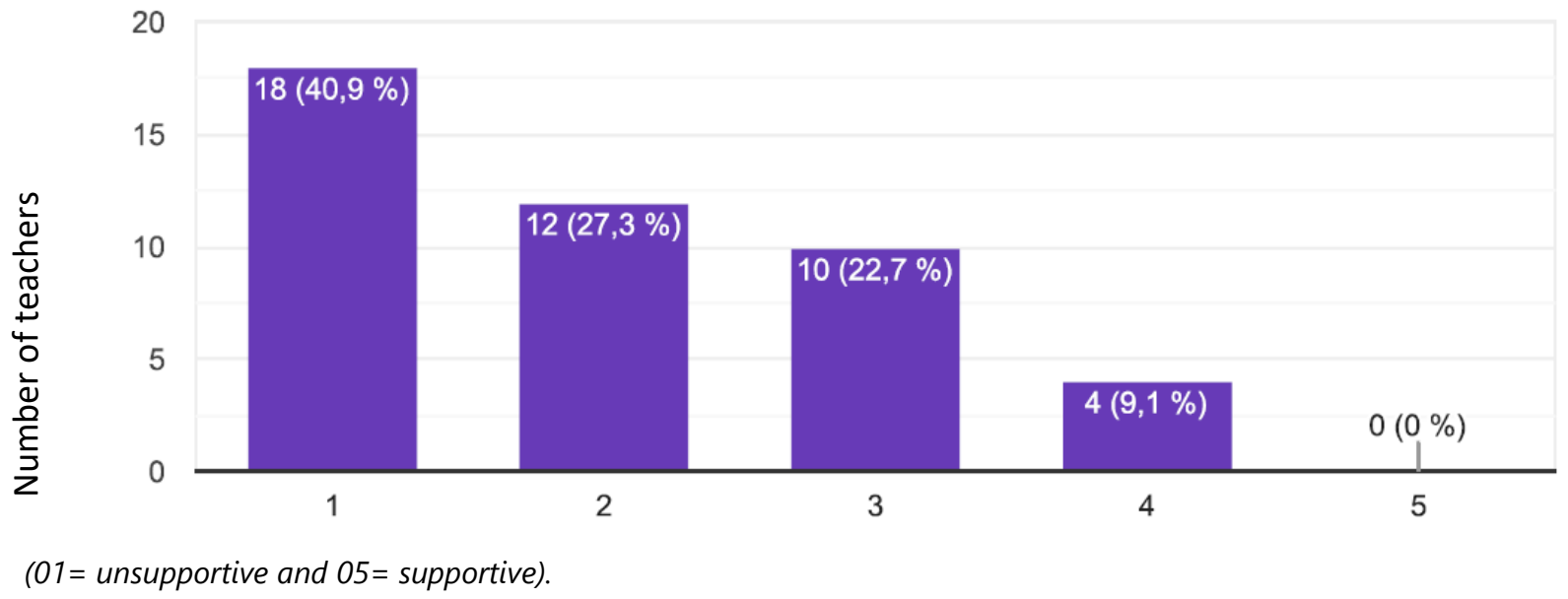

Communication between educational bodies and teachers is not exemplary, and COVID 19 deepened the void. Less than 5\% of respondents felt some support from educational authorities. In the interview, teachers debated the need for effective communication between policymakers and local agents. They argued that in times of change, such as a pandemic, the central 
government should delegate some of its powers to local agents. However, local authorities' ability to self-managing the crisis is subject to scrutiny

\subsection{Self-management}

This paper considers self-management a significant factor in English language acquisition. Spolsky defined self-management as "attempts to expand personal repertoires to enhance communication and employability" (2018, p.04). Self-management in this study and self-directed learning are two sides of the same coin.

Figure 4: Teachers self-directed learning belief

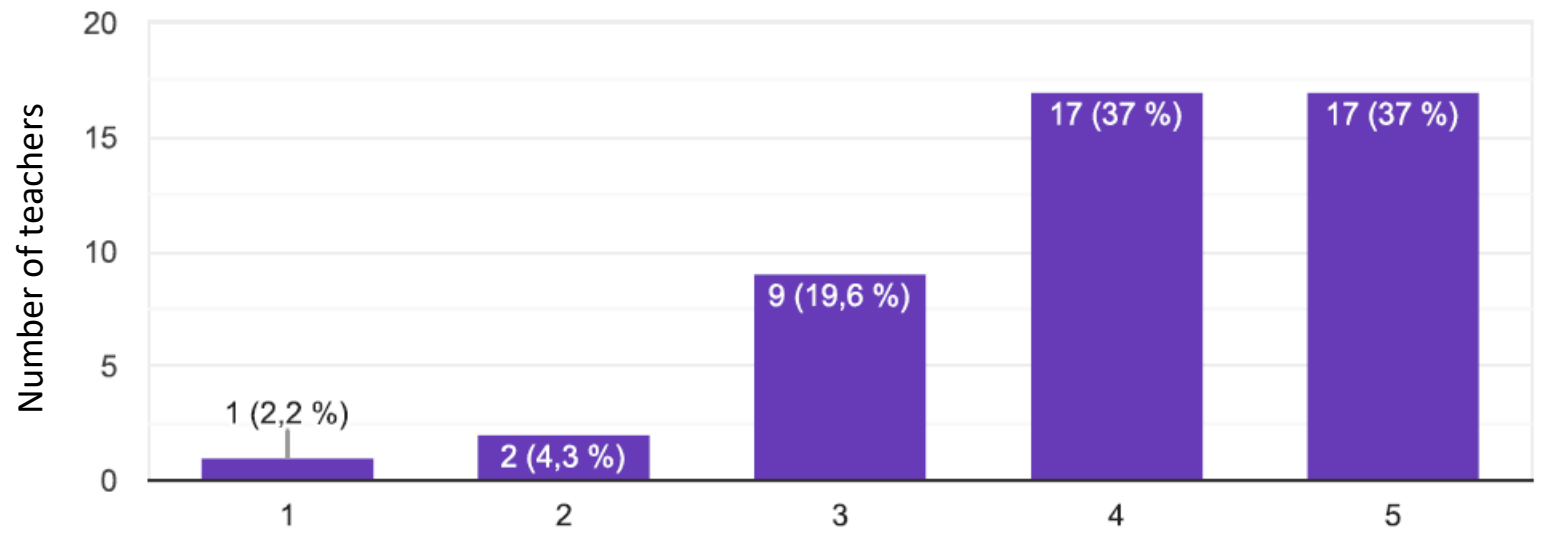

(01 = not really autonomous and 05= very autonomous)

The data shows that $74 \%$ of teachers believe in their self-reliance. During the interview, teachers argued that this fact is justified by two significant motives: the need to grow professionally and their linguistic proficiency. As university students, teachers believed that learning choices and routes should be made individually. Learning in higher education is a reflection of natural development. As we grow, our autonomy and independence grow. The respondents expressed their belief that self-directed learning is a remarkable professional development feature. Besides, language is another encouraging factor. Using a global language such as English eased access to a rich knowledge resource. The majority of teachers attended live webinars, conferences, and training online during the pandemic and compiled various leading institutions certificates. The common concern was how to pass down the power of self-directed learning to young students.

\section{Discussion of results}

This preliminary study's findings indicate that according to Guglielmino scale, teachers of English in the directorate of Chichaoua show a high degree of readiness to sustain language policy creation. Ricento and Hornberger argued that 'rather than accept this broad goal, ESL teachers may, for example, opt for a participatory approach that centres on students' rather than society's needs (1996, p.421). The data portrayed ESL teachers in the directorate of Chichaoua as self-reliant and a primary source of support for students. More surprisingly, the results show that novice teachers (from 01 to 05 years of experience) are more susceptible to resist central policies and express vivid readiness to sustain a local language policy.

\section{Conclusion}

This study's primary purpose was to investigate ESL teachers' readiness for sustaining a self-directed learning policy using Guglielmino's scale. Although the fieldwork involved mixed methods, we could not generalize the findings. This research's primary finding was that young teachers (with less than five years of experience) show a greater readiness to contribute to creating a language policy that advocates self-directed learning in an ESL classroom. Further research on using the Guglielmino self-directed learning readiness scale (SDLRS) involving young ESL teachers will be of great value.

\section{References}

[1] Baldauf Jr., R. B. (2012). Introduction to Language Planning: Where have we been? Where might we be going? RBLA, Belo Horizonte, 12(02), 233-248.

[2] Cooper, R. L. (1989). Language planning and social change. Cambridge: Cambridge University Press.

[3] Fishman, J. A. (1974). Advances in Language Planning. The Hague: Mouton.

[4] Francis M. Hult \& D. Johnson, C. (2015). Research Methods in Language Policy and Planning. Chichester: Wiley Blackwell.

[5] Guglielmino, P. J., \& Roberts, D. G. (1992). A comparison of self-directed learning readiness in U.S. and Hong Kong samples and the implications for job performance. Human Resource Development Quarterly, 3(3), 261-271. https://doi.org/10.1002/hrdq.3920030307 Holec, H. (1981). Autonomy in foreign language learning (first published 1979, Strasbourg: Council of Europe). Oxford: Pergamon.

[6] Hornberger, N. H. (1994). Literacy and language planning. Language and Education. 08(01-02), 75-86. DOI: 10.1080/09500789409541380. 
[7] Hornberger, R. T. (1996). Unpeeling the Onion: Language Planning and Policy and The ELT Professionals. TESOL Quarterly, $401-427$.

[8] Knowles, M. (1975). Self-directed learning. . Chicago: Follett Publishing company.

[9] Spolsky, B. (2009). Language management. New York: Cambridge University Press.

[10] Spolsky, B. (2012). What is Language Policy? In B. Spolsky, The Cambridge Handbook of Language Policy (pp. 3-16). Cambridge: Cambridge University Press.

[11] Spolsky, B. (2018). A modified and enriched theory of language policy (and management). Language Policy, 323-338. DOI https://doi.org/10.1007/s10993-018-9489- 